\title{
Factors Influencing Male Involvement in Antenatal Care in the Kassena Nankana Municipal in the Upper East Region, Ghana
}

\author{
Maxwell Tii Kumbeni, MSc, BSc \\ Nabdam District Health Directorate, Ghana Health Service, Nangodi, Ghana \\ Florence Assibi Ziba, MSc, BSc \\ Department of Nursing, University for Development Studies, Tamale, Ghana \\ John Ndebugri Alem, MPHIL, BSc \\ War Memorial Hospital, Ghana Health Service, Navrongo, Ghana \\ Sylvia Apana Nborah, BSc \\ Nabdam District Health Directorate, Ghana Health Service, Nangodi, Ghana \\ Doi:10.19044/esj.2019.v15n21p1～ＵRL:http://dx.doi.org/10.19044/esj.2019.v15n21p1
}

\begin{abstract}
Background: Globally, male involvement in antenatal care remains a challenge to the effective utilization of maternal health services. Male involvement is considered to be a useful tool that is capable of improving the health outcome of mothers and their children. However, matters relating to antenatal care have often been considered on a gender basis. Objective: The objective of this study was to assess the factors that influence male partner involvement in antenatal care services. Methods: A community-based crosssectional study was conducted among 420 men whose partners were pregnant or had delivered within twelve months preceding the study using multiple sampling procedures. Pearson Chi-Square and Fisher's exact test were conducted to establish an association between dependent and independent variables after which multiple logistic regression was conducted. P-values of $<0.05$ at $95 \%$ confidence interval were considered significant. Data were analyzed using STATA version 13.1. Results: The level of male involvement in antenatal care was high (67.2\%). About $71.9 \%$ accompanied their partners to antenatal clinics at one point during the pregnancy period. Out of this, $45.7 \%$ of them did so four or more times, $35.7 \%$ went two to three times, while $18.6 \%$ went only once. Factors such as staff attitude, time spent at the clinics, age, educational level, monthly income level, living with a partner during pregnancy, distance to the clinic, and community acceptability were all statistically significant to male involvement. Conclusion: The level of male involvement was high and considered above average. There is the need to
\end{abstract}


develop interventions that will diffuse the existing socio-cultural perceptions and improve staff attitudes to achieve higher male involvement in antenatal care.

Keywords: Male involvement, Antenatal care, Pregnancy, Maternal health

\section{Introduction}

The World Health Organization predicts a world where every pregnant woman and newborn receives quality care throughout the pregnancy, childbirth, and the postnatal period (WHO, 2016a). There is widespread evidence that antenatal care (ANC) is very crucial in the reduction of maternal mortality and morbidity (Miltenburg et al., 2017; Sumankuuro et al., 2017). The recommendations of World Health Organization (WHO) on maternal health care promotion interventions encourage active male partner involvement in ANC delivery as well as postnatal care to improve upon the health outcome of both mothers and their children (WHO, 2016a). In the past years, however, matters relating to maternal health care have often been considered on a gender basis. This has the potential to influence policy, programs, and practices on how male partners may get involved in ANC (Lewis et al., 2015). In sub-Saharan Africa, it is rare to find male partners at the antenatal clinics. It may be considered unthinkable in some communities to see men going with their partners for ANC checkups (Babalola \& Fatusi, 2009; Dharma, 2013). Meanwhile, within that socio-cultural context, it is the men who have the sheer power in the family in terms of decision making (Story \& Burgard, 2012). Since men are mostly decision makers in the family, some scholars argue that male partner involvement in ANC is very crucial in addressing the first two of the three delays that contribute to maternal mortality (Allendorf, 2007; Fekede et al., 2014).

Male involvement has been defined as the willingness of male partners to acknowledge and participate in maternal health issues (Byamugisha et al., 2010). It refers to men acting together with their partners at all levels and supporting decisions and practices that will enhance the wellbeing of women. For example, this entails accompanying their partners to ANC clinics, supporting financially for ANC activities, discussing health issues relating to the pregnancy with their partners among others (Byamugisha et al., 2010; Mullany, Hindin, \& Becker, 2005). However, several studies have reported low levels of male involvement in ANC across Africa. An analysis of Demographic and Health Surveys (DHS) across eight selected African countries indicated that an average of less than half $(45.7 \%)$ of men ever accompanied their partners for ANC checkup. Burundi recorded the lowest proportion at $18.2 \%$ (Jennings et al., 2014). A study in Ethiopia found that $26.5 \%, 11 \%$, and $3 \%$ of men respectively saved money, arranged for 
transportation, and identified a health facility towards birth preparedness of their partners (Mersha, 2018). A recent study conducted in under-served communities in Accra, Ghana, by Atuahene et al. (2017) found out that out of 256 participants, only $47(8.4 \%)$ men ever accompanied their partners to ANC clinics. Even out of the 47, 40.4\% accompanied their partners to ANC clinics only once, $51.1 \%$ went twice, and only $8.5 \%$ went with their partners at least four times.

Some studies have examined the factors that influence male partner involvement in maternal health care programs in Africa. In Kenya, even though men were fully aware of the benefits of their support in maternal health, factors such as pregnancy support being viewed as the female role in society, poor attitude of health staff, and unfriendly ANC services limited their involvement (Ganle \& Dery, 2015; Kwambai et al., 2013). A study in Malawi also found that the most effective and sustainable way to encourage male partner involvement is through the use of male peers (Kululanga et al., 2012). Another study in Uganda that examined the perceived benefits of male involvement in ANC found out that having knowledge of at least three ANC services, getting health information from the health staff, and a partner having delivered the last child in the health facility were all factors that increased male involvement in ANC (Tweheyo et al., 2010). Recent studies in Ghana indicates that men are not necessarily indifferent towards maternal healthcare. Rather, they operationalized their care within the spaces allowed for them by the society (Bougangue \& Ling, 2017). Aborigo et al. (2018) also found that restricted access to men at the health facilities, as well as negative behavior of health staff, are barriers to male involvement in ANC. Nonetheless, negative opinions and attitude by the majority of women towards male involvement in ANC was a limitation to male partner participation in Ghana (Adongo et al., 2013; Ganle et al., 2016). This probably accounts for the apathy and lack of interest.

Most studies in Ghana concerning male involvement in maternal health care have focused more on modern contraception. Furthermore, the few studies that looked at male participation in ANC focused more on men accompanying their partners to ANC clinics while neglecting other forms of involvement such as financial support, performing household chores, discussing health issues relating their partners' pregnancy among others. This study assessed male participation using six key factors adopted from Byamugisha et al. (2010) to quantify the level of male involvement in ANC services of their partners. 


\section{Methods}

\section{Study Design and Setting}

This was a community-based cross-sectional study which employed the use of a quantitative method of data collection. The questionnaire contained only closed-ended questions and face-to-face interview was done to gather data from participants. Where applicable, the questions were explained verbally in the local dialect (Kasem or Nankam) for those who could not understand English. Field workers who were involved in the data collection were trained in the local dialect - reverse translation to ensure uniformity in explaining the questions to respondents in the local dialect. The study was conducted from February to April 2019.

The Kassena Nankana Municipal forms part of the fifteen (15) Municipalities and Districts in the Upper East Region. The distance from the municipal to the national capital, Accra, is over $800 \mathrm{~km}$. The municipal has a total population of 130,593 with women in their reproductive age being 31,342 (Ghana Health Service, 2018). There are two main ethnic groups (Kassena and Nankani) which share a lot of similarities in cultural practices. The municipality is mostly patriarchal with male dominance which allows the practice of polygamy. The settlement is mainly dispersed with extended family units living together in compound houses and headed by males with absolute authority. The municipality is endowed with a good number of institutions. Notably among them are the War Memorial Hospital and the Navrongo Health Research Center. The municipality is divided into eight sub municipals with at least one health center in each sub municipal and several Community-based Health Planning and Service (CHPS) compounds. There are also a few mission clinics and private health facilities operating in the municipality.

\section{Study Population}

The study population involved men (18-60 years) whose partners were pregnant and were ANC attendants as well as men whose partners delivered in the last 12 months as of the time of this study and were also ANC attendants. The 12 months' grace period was employed to prevent recall bias from participants.

\section{Sample Size}

The level of male involvement in ANC in Ghana using the Byamugisha et al. (2010) index is unknown. Therefore, the level of involvement is estimated at 50\%. Using Epilnfor version 7.2 with $95 \% \mathrm{CI}$ and a 5\% acceptable margin of error, the sample size was estimated at 379 . The estimated sample size was rounded up to 420 to cater for an estimated 10 percent non-response rate. 


\section{Sampling Procedure}

Multiple stage sampling technique was employed in the selection of participants. Firstly, a computer-based number generator was used to select 420 houses to be included in the study randomly. This was done using the sample frame generated from the 2010 Population and Housing Census data. One eligible respondent was interviewed in each house, and where there was more than one eligible respondent in a house, a simple random sampling method was used to select one respondent. Where there was no eligible respondent in a selected house, the next house was considered.

\section{Measurement}

The outcome variable is male involvement (binary) and was measured on a scale of six points adopted from Byamugisha et al. (2010) index with equal weight in the score;

1. The man makes joint plans with partner for emergency situations during pregnancy

2. The man attends ANC with partner

3. The man provides funding for ANC activities

4. The man helps in performing household chores

5. The man discusses with partner on issues occurring during ANC

6. The man discusses with partner's healthcare provider on partner's pregnancy

Each activity was given a score of one (1) if performed and zero (0) if not performed. A total score of between 0-3 was considered low level of male involvement, while a score of between 4-6 was considered high level of male involvement.

\section{Data Analysis}

Simple proportions were used to describe categorical data at univariate level and presented in frequency and percentage distributions. At bivariate level, Pearson's Chi-Square and Fisher's exact test were used to determine the associations between the independent and dependent variables. Du Prel et al. (2010) argued that, if the frequency of success in a binary sample is to be compared, Fisher's exact test is the most suitable test particularly in small samples. For large samples $(n>60)$, the Chi-Square test is the best option. The computed Chi-Square and Fisher's exact test were compared to the critical value 0.05 level of significance at a $95 \%$ confidence interval. A relationship between the independent and dependent variable that resulted in a critical pvalue of less than 0.05 was interpreted as being significant.

All the variables that were found to be significant at the bivariate level were included in a logistic regression model to determine the relationship 
between the variables and the dependent variable. The analysis was done using STATA version 13.1 .

\section{Ethical Approval}

Approval was sought from Ghana Health Service through the Kassena Nankana municipal health directorate after which further approval was sought from the traditional leaders of the various communities. Written informed consent was also obtained from all the study participants.

\section{Results}

\section{Socio-Demographic Characteristics}

Below is a description of the socio-demographic characteristics of the participants. The response rate for the study was 96\%. Majority (67.8\%) of the participants were aged 40 years and below while the rest were older than 40 years. About $67.2 \%$ of the participants had tertiary education, $28.8 \%$ had education up to junior or senior high school, while only $4 \%$ had no formal education. Monthly income earners of GHC 599 and below were $32.6 \%$ while those earning GHC 600 and above were $67.4 \%$. Christians were the majority $(75.3 \%)$ in this study, and the least were African Traditional worshippers (4.2\%). Men who lived with their partners during pregnancy were $92.1 \%$. All the variables except for 'number of children and living with partner's other family members' were statistically significant to male involvement at the bivariate level (p-values <0.05) (Table 1).

Table 1. Socio-demographic characteristics $(n=405)$

\begin{tabular}{|c|c|c|}
\hline Characteristic & Frequency $(\%)$ & P-value \\
\hline Age & & 0.006 \\
\hline $20-30$ years & $84(20.7)$ & \\
\hline $31-40$ years & $191(47.1)$ & \\
\hline $41-50$ years & $108(26.8)$ & \\
\hline $51-60$ years & $22(5.4)$ & \\
\hline Educational level completed & & 0.002* \\
\hline No education & $16(4.0)$ & \\
\hline Junior high school & $18(4.4)$ & \\
\hline Senior high school & $99(24.4)$ & \\
\hline Tertiary and above & $272(67.2)$ & \\
\hline Employment status & & $<0.001$ \\
\hline Unemployed & $48(11.8)$ & \\
\hline Private employment & $121(29.9)$ & \\
\hline Government employment & $246(58.3)$ & \\
\hline Monthly income level (GHC) & & 0.021 \\
\hline$<100$ & $32(8.0)$ & \\
\hline $100-299$ & $48(11.8)$ & \\
\hline $300-599$ & $52(12.8)$ & \\
\hline $600-1000$ & $92(22.7)$ & \\
\hline$>1000$ & $181(44.7)$ & \\
\hline
\end{tabular}




\begin{tabular}{|c|c|c|}
\hline Religion & & $0.028 *$ \\
\hline Christianity & $305(75.3)$ & \\
\hline Islamic & $88(20.5)$ & \\
\hline African Traditional & $17(4.2)$ & \\
\hline Number of children & & 0.709 \\
\hline 1 & $95(23.5)$ & \\
\hline 2 & $109(26.9)$ & \\
\hline 3 & $122(30.1)$ & \\
\hline$\geq 4$ & $79(19.5)$ & \\
\hline Living with partner during pregnancy & & $<0.001$ \\
\hline Yes & $373(92.1)$ & \\
\hline No & $32(7.9)$ & \\
\hline $\begin{array}{l}\text { Other family members living with partner } \\
\text { during pregnancy }\end{array}$ & & 0.372 \\
\hline Yes & $268(66.2)$ & \\
\hline No & $137(33.8)$ & \\
\hline
\end{tabular}

Fisher's exact test*

\section{Male Involvement}

Majority $(86.9 \%)$ of the participants said they planned the pregnancy with their partners. About $77.5 \%$ of the participants made joint plans with their partners for emergency situations in pregnancy, and $71.9 \%$ ever accompanied their partners to ANC clinics. Of those who accompanied their partners to ANC clinics, $45.7 \%$ of them did so at least four times, $35.7 \%$ went two to three times while $18.6 \%$ went with their partner to the ANC clinics only once. Reasons cited for not accompanying their partners to the clinics were lack of time $(72.8 \%)$, and it is for only women to handle $(27.2 \%)$.

About $86.7 \%$ of the study participants provided funding for their partners during pregnancy to support ANC visits, and $75.8 \%$ of them supported with household chores during their partners' pregnancy. The mean score for male involvement was $4.28 \pm 1.62$ with a minimum score of zero point and a maximum score of six points. Low male involvement was $32.8 \%$, while high male involvement was $67.2 \%$ (Table 2).

Table 2. Male involvement

\begin{tabular}{|l|l|}
\hline Variable & $\begin{array}{l}\text { Frequency } \\
(\%)\end{array}$ \\
\hline Was the pregnancy planned? & \\
\hline Yes & $352(86.9)$ \\
\hline No & $53(13.1)$ \\
\hline $\begin{array}{l}\text { Did you make joint plans for emergency situation during the } \\
\text { pregnancy?* }\end{array}$ \\
\hline Yes & $314(77.5)$ \\
\hline No & $91(22.5)$ \\
\hline Did you ever accompanied your partner to the ANC clinic** & \\
\hline Yes & $291(71.9)$ \\
\hline No & $114(28.1)$ \\
\hline
\end{tabular}




\begin{tabular}{|l|l|}
\hline If yes, how many times? & \\
\hline Once & $54(18.6)$ \\
\hline Two to three times & $104(35.7)$ \\
\hline Four or more times & $133(45.7)$ \\
\hline If no, why did you not accompany your partner to the ANC clinic & \\
\hline I did not have the time to do so & $83(72.8)$ \\
\hline It is an issue for women to handle & $31(27.2)$ \\
\hline Did you provide funding for ANC visits?* & \\
\hline Yes & $351(86.7)$ \\
\hline No & $54(13.3)$ \\
\hline Helped in performing household chores during partner pregnancy* & \\
\hline Yes & $307(75.8)$ \\
\hline No & $98(24.2)$ \\
\hline Discussed with partner on issues occurring during ANC services* & \\
\hline Yes & $288(71.1)$ \\
\hline No & $117(28.9)$ \\
\hline $\begin{array}{l}\text { Discussed health issues relating to partner's pregnancy with her } \\
\text { healthcare providers* }\end{array}$ & \\
\hline Yes & $182(44.9)$ \\
\hline No & $223(55.1)$ \\
\hline Score for male involvement & \\
\hline Min & 0 point \\
\hline Max & 6 points \\
\hline Mean \pm standard deviation & $4.28 \pm 1.62$ \\
\hline Level of male involvement & \\
\hline Low & $133(32.8)$ \\
\hline High & $272(67.2)$ \\
\hline
\end{tabular}

\section{Health Facility and Cultural-Related Factors}

For participants who ever accompanied their partners to ANC clinics, 224 (77\%) of them said the health care providers were friendly while $67(33 \%)$ said the care providers were unfriendly. About 204 (70.1\%) of them also thought that the time they spent at the ANC clinics with their partners was reasonable, but 87 (29.9\%) thought that they spent so much time with their partners at the ANC clinics. Motorbikes were the most common means of transport to the ANC clinic for 257 (63.5\%) of the participants, 88 (21.7\%) of the participants walked, 36 (8.9\%) used cars (public transport), and 24 (5.9\%) used bicycles.

Close to half $177(43.7 \%)$ participants were of the view that it is not acceptable by the community for men to accompany their partners to ANC clinics while $228(56.3 \%)$ said it is acceptable. Meanwhile, 155 (38.3\%) said it is not also acceptable by their family and friends for men to accompany their partners to ANC clinics while $250(61.7 \%)$ said that it is acceptable by their family and friends. Except for the cost of transportation, which is not significantly associated with male participation ( $p$-value $=0.908$ ), all the other 
variables were statistically related to male participation at the bivariate leve (Table 3).

Table 3. Health facility and cultural related factors

\begin{tabular}{|c|c|c|}
\hline Variable & Frequency $(\%)$ & P-value \\
\hline $\begin{array}{l}\text { How would you assess the attitude of the staff when } \\
\text { you accompanied your partner to ANC clinic? }\end{array}$ & & $<0.001$ \\
\hline Friendly & $224(77.0)$ & \\
\hline Unfriendly & $67(23.0)$ & \\
\hline $\begin{array}{l}\text { How would you assess the amount of time you spent } \\
\text { at the ANC clinic with your partner? }\end{array}$ & & $<0.001$ \\
\hline Reasonable & $204(70.1)$ & \\
\hline Too long & $87(29.9)$ & \\
\hline By what means did your partner go to ANC clinic? & & $\mathbf{0 . 0 1}$ \\
\hline Walk & $88(21.7)$ & \\
\hline Bicycle & $24(5.9)$ & \\
\hline Motor bike & $257(63.5)$ & \\
\hline Car & $36(8.9)$ & \\
\hline How do you assess the cost of transport to ANC? & & 0.908 \\
\hline Expensive & $139(34.3)$ & \\
\hline Not expensive & $176(43.5)$ & \\
\hline Cheap & $90(22.2)$ & \\
\hline $\begin{array}{l}\text { How do you rate the distance from your home to the } \\
\text { ANC clinic? }\end{array}$ & & 0.005 \\
\hline Very far & $26(6.4)$ & \\
\hline Far & $158(39.0)$ & \\
\hline Near & $173(42.7)$ & \\
\hline Very near & $48(11.9)$ & \\
\hline $\begin{array}{l}\text { Do you think your community consider it acceptable } \\
\text { for a man to accompany his partner to ANC clinic? }\end{array}$ & & $<0.001$ \\
\hline Yes & $228(56.3)$ & \\
\hline No & $177(43.7)$ & \\
\hline $\begin{array}{l}\text { Do you think your family and friends consider it } \\
\text { acceptable for a man to accompany his partner to } \\
\text { ANC clinic? }\end{array}$ & & 0.004 \\
\hline Yes & $250(61.7)$ & \\
\hline No & $155(38.3)$ & \\
\hline $\begin{array}{l}\text { Do you think men who discuss matters relating to } \\
\text { pregnancy with their partners are interfering in } \\
\text { their privacy? }\end{array}$ & & $<0.001$ \\
\hline Yes & $109(26.9)$ & \\
\hline No & $296(73.1)$ & \\
\hline
\end{tabular}

Multivariate Logistic Regression Analysis of Factors Associated with Male Involvement in ANC

In the adjusted module, poor health staff attitude as well as delays during ANC visits decreased the odds of high male involvement in ANC [aOR $=0.41,95 \%$ CI: $0.17-0.99$, p-value <0.05]. Participants aged $41-50$ years 
were almost three times more likely to highly engage in activities that support their partners during pregnancy when compared with those aged 20-30 years $[\mathrm{aOR}=2.18,95 \% \mathrm{CI}: 1.06-4.51$, p-value<0.05]. The odds of high male involvement for men who did not stay with their partners during ANC reduced by $0.65[\mathrm{aOR}=0.35,95 \% \mathrm{CI}$ : 0.09-0.59 $\mathrm{p}$-value $<0.01]$ when compared with those who stayed with their partners during pregnancy.

The odds of high male involvement in ANC activities in communities where it is considered unacceptable for men to accompany their partners to ANC clinics is decreased by 0.55 compared to communities where it is acceptable for men to accompany their partners to the ANC clinics $[\mathrm{aOR}=$ 0.45, 95\% CI: 0.22-0.88, p-value <0.05] (Table 4).

Table 4. Multivariate logistic regression analysis of factors associated with male involvement in ANC

\begin{tabular}{|c|c|c|}
\hline Variables & $\begin{array}{l}\text { Crude odds ratio } \\
(95 \% \text { CI })\end{array}$ & $\begin{array}{l}\text { Adjusted odds ratio } \\
(95 \% \text { CI })\end{array}$ \\
\hline \multicolumn{3}{|c|}{$\begin{array}{l}\text { How would you assess the attitude } \\
\text { of the staff when you accompanied } \\
\text { your partner to ANC clinic? }\end{array}$} \\
\hline Friendly & 1.0 & 1.0 \\
\hline Unfriendly & $0.24(0.11-0.50)^{* * * *}$ & $0.41(0.17-0.99)^{*}$ \\
\hline \multicolumn{3}{|c|}{$\begin{array}{l}\text { How would you assess the amount } \\
\text { of time you spent at the ANC clinic } \\
\text { with your partner? }\end{array}$} \\
\hline Reasonable & 1.0 & 1.0 \\
\hline Too long & $0.25(0.12-0.52)^{* * *}$ & $0.41(0.17-0.99)^{*}$ \\
\hline \multicolumn{3}{|l|}{ Age } \\
\hline $20-30$ years & 1.0 & 1.0 \\
\hline $31-40$ years & $1.38(0.81-2.35)$ & $1.29(0.67-2.50)$ \\
\hline $41-50$ years & $2.38(1.25-4.52)^{*}$ & $2.91(1.31-6.45) * *$ \\
\hline 51-60 years & $0.57(0.22-1.47)$ & $0.57(0.17-1.86)$ \\
\hline \multicolumn{3}{|c|}{ Educational level completed } \\
\hline No education & 1.0 & 1.0 \\
\hline Junior high school & $1.25(0.32-4.93)$ & $0.12(0.02-0.75) *$ \\
\hline Senior high school & $1.20(0.41-3.47)$ & $0.15(0.03-0.72) *$ \\
\hline Tertiary and above & $2.78(0.99-7.74)$ & $0.21(0.03-1.09)$ \\
\hline \multicolumn{3}{|l|}{ Employment status } \\
\hline Unemployed & 1.0 & 1.0 \\
\hline Private employment & $0.63(0.32-1.26)$ & $0.82(0.32-2.10)$ \\
\hline Government employment & $1.94(0.99-3.74)$ & $2.19(0.68-7.12)$ \\
\hline \multicolumn{3}{|c|}{ Monthly income level (GHC) } \\
\hline$<100$ & 1.0 & 1.0 \\
\hline $100-299$ & $0.45(0.17-1.19)$ & $0.18(0.05-0.63)^{* * *}$ \\
\hline $300-599$ & $0.62(0.24-1.59)$ & $0.35(0.10-1.24)$ \\
\hline $600-1000$ & $1.29(0.53-3.12)$ & $0.44(0.12-1.74)$ \\
\hline$>1000$ & $1.09(0.49-2.48)$ & $0.17(0.04-0.69) *$ \\
\hline Religion & & \\
\hline
\end{tabular}




\begin{tabular}{|l|l|l|}
\hline Christianity & 1.0 & 1.0 \\
\hline Islamic & $\mathbf{0 . 6 0}(\mathbf{0 . 3 6 - 0 . 9 9}) *$ & $0.69(0.38-1.26)$ \\
\hline African Traditional & $0.37(0.14-1.00)$ & $0.29(0.07-1.19)$ \\
\hline
\end{tabular}

Key: *=p-value $<0.05, * * \mathrm{P}$-value $<0.01, * * * \mathrm{p}$-value $<0.001$

Table 4. cont. Multivariate logistic regression analysis of factors associated with male involvement in ANC

\begin{tabular}{|c|c|c|}
\hline \multicolumn{3}{|l|}{$\begin{array}{l}\text { Living with partner during } \\
\text { pregnancy }\end{array}$} \\
\hline Yes & 1.0 & \\
\hline No & $0.22(0.10-0.48) * * *$ & $0.35(0.09-0.59) * *$ \\
\hline \multicolumn{3}{|c|}{\begin{tabular}{l|l} 
By what means did your partner & \\
go to ANC clinic? &
\end{tabular}} \\
\hline Walk & 1.0 & 1.0 \\
\hline Bicycle & $0.47(0.19-1.20)$ & $0.35(0.11-1.12)$ \\
\hline Motor bike & $1.66(1.00-2.77) *$ & $1.60(0.74-3.45)$ \\
\hline Car & $1.50(0.65-3.46)$ & $2.19(0.64-7.54)$ \\
\hline \multicolumn{3}{|l|}{$\begin{array}{l}\text { How do you rate the distance } \\
\text { from your home to the ANC } \\
\text { clinic? }\end{array}$} \\
\hline Very far & 1.0 & 1.0 \\
\hline Far & $4.42(1.80-10.86)^{* * * *}$ & $2.77(0.88-8.66)$ \\
\hline Near & $3.26(1.36-7.78) * * *$ & $2.51(0.79-7.92)$ \\
\hline Very near & $2.67(0.96-7.37)$ & $4.48(1.11-18.17)^{*}$ \\
\hline \multicolumn{3}{|l|}{$\begin{array}{l}\text { Do you think your community } \\
\text { consider it acceptable for a man } \\
\text { to accompany his partner to } \\
\text { ANC clinic? }\end{array}$} \\
\hline Yes & 1.0 & 1.0 \\
\hline No & $0.43(0.26-0.62) * * *$ & $0.45(0.22-0.88)^{*}$ \\
\hline \multicolumn{3}{|c|}{$\begin{array}{l}\text { Do you think your family and } \\
\text { friends consider it acceptable } \\
\text { for a man to accompany his } \\
\text { partner to ANC clinic? }\end{array}$} \\
\hline Yes & 1.0 & 1.0 \\
\hline No & $0.54(0.35-0.83) * * *$ & $1.14(0.54-2.40)$ \\
\hline \multicolumn{3}{|c|}{$\begin{array}{l}\text { Do you think men who discuss } \\
\text { matters relating to pregnancy } \\
\text { with their partners are } \\
\text { interfering in their privacy? }\end{array}$} \\
\hline Yes & 1.0 & 1.0 \\
\hline No & $2.84(1.78-4.55) * * *$ & $2.20(1.12-4.33) *$ \\
\hline
\end{tabular}

Key: $*=$ p-value $<0.05, * * P$-value $<0.01, * * *$ p-value $<0.001$

\section{Discussion}

This study examined factors influencing male involvement in antenatal care of their partners. Overall, the level of high male involvement was above 
average. Many of the participants planned the pregnancies with their partners, accompanied them to ANC for at least four times or more, and assisted them with the house chores. However, the lack of time was the main reason for males not being involved in ANC.

The study revealed that $67.2 \%$ scored high for male involvement while only $32.8 \%$ scored low for male involvement. These findings are higher than other studies conducted in Africa on male involvement in ANC (Aborigo et al., 2018; Atuahene et al., 2017; Jennings et al., 2014). The difference in the findings could be attributed to the fact that these studies considered male involvement based on men accompanying their partners to the ANC clinics while neglecting several other support that men give to their partners during ANC. While many men may deem it their responsibility to provide and support their wives during pregnancy, they may not see accompanying them to ANC as part of that duty. Male involvement goes beyond just accompanying one's partner to the ANC clinics. It also includes providing all other necessary support at home during pregnancy that will enhance the good health outcome of the mother and baby. This study, however, corroborated with a study conducted in the central region of Ghana where it was reported that although men are generally involved in ANC activities at the household and community level, they were not directly involved in activities such as accompanying their partners to the ANC clinics (Bougangue \& Ling, 2017).

Additionally, $71.9 \%$ of the men have accompanied their partners to the ANC clinics, with $45.7 \%$ making at least four visits with their partners. The preferred standard is for pregnant women to make eight contacts with their health care providers before putting to birth (WHO, 2016b). The current finding of less than half of the men ever accompanying their partners to the ANC clinics for at least four times means that fewer men are regularly accompanying their partners to ANC clinics. This finding agrees with those reported in Uganda, where $65.4 \%$ of men were found to have accompanied their partners to the ANC clinic only once (Sinha, 2008). Reasons cited for men not accompanying their partners to ANC clinics were lack of time and cultural issues. Similar findings were reported in previous studies (Aborigo et al., 2018; Bougangue \& Ling, 2017). On the contrary, Jambeidu (2017) found attitudes, subjective norms, and behavioural intentions of men as the main factors that influence low involvement of men in accompanying their partners to ANC clinics.

According to the present study, more than $70 \%$ of the men made joint plans with their partners for emergencies in pregnancy, provided funding for their partners during pregnancy to support ANC visits, as well as assisted with household chores during their partners' pregnancy. They also discussed issues relating to the pregnancy with their partners, and close to half of them took a step further to discuss matters relating to their partners' pregnancy with the 
healthcare providers. In a similar study by Byamugisha et al. (2010) in Uganda, over $90 \%$ of men provided financial support to their partners during ANC. However, less than one-third of them made time to discuss health issues regarding the pregnancy with their partners or their partners' healthcare providers. These differences could be attributed to variation in demographic variables of the participants.

Moreover, poor health staff attitudes and delays during ANC visits encountered by men, reduced the likelihood of high male involvement. Friendly staff attitudes encourage men to accompany their partners to ANC clinics as well as support them in other maternal health issues such as funds for running laboratory test, discussing issues relating to the pregnancy among others. If men also feel that time spent during ANC sessions is taking more than they expected, they were likely not to accompany their partners to the ANC clinics because of their busy schedules (Ganle \& Dery, 2015; Kwambai et al., 2013; Steen et al., 2012; Tweheyo et al., 2010). This study also found that men aged 41 to 50 years are more likely to engage in male involvement than those younger than 41 years. Also, men with no formal education of any sort were more likely to get involved in the ANC activities of their partners than those with any level of formal education. Similar findings are reported by Dharma (2013) in Nepal, India, where he found that men with higher age and uneducated had high level of male involvement.

Participants who did not live with their partners during pregnancy were found to engage in low male involvement according to the current study. It was thought that because of proximity and time, men who live with their partners during pregnancy were more likely to support them with household chores, accompany their partners to ANC clinics, and discuss health matters relating to the pregnancy with their partners and partners' healthcare providers. Living close to the ANC clinic also increased the chances of high male involvement during ANC as found by this study. These findings are consistent with those by Muki, (2009), that showed that long distances traveled to the ANC clinic reduced the likelihood of maternal care utilization and high male involvement in Uganda.

Unacceptability by the community for men to accompany their partners to the ANC clinic is highly associated with low male involvement. This could be attributed to traditional cultural norms regarding marital roles in the community. Culture forms an integral part of the daily living in the traditional setting where the man is the head of the family, whereas the responsibility of the woman is childbearing and the upbringing of children although these roles are being challenged. The study confirms the challenge in many other African countries such as South Africa and Malawi where childbearing is seen as the domain of women (Kululanga et al., 2012; Mullick et al., 2005). However, men who thought that discussing pregnancy issues 
with their partners is not an intrusion of privacy to women were more than two times likely to be engaged in high male involvement.

\section{Strengths and Limitations}

The strength of this study is that it included six variables to assess the level of male involvement in ANC activities. This makes it different from other studies and gives a holistic assessment of how men support their partners in various forms during pregnancy. One limitation of this study is that we relied upon self-reported behavior on the part of men without including direct observation. The second limitation is that this study was conducted in the urban and peri-urban and may not reflect the ideas of men in rural areas.

\section{Conclusion}

This study found high male involvement in ANC activities in the Kassena Nankana municipal as above average. Male partner involvement in antenatal care is influenced by varied factors such as staff attitude, time spent at the clinics, age, educational level, monthly income level, living with partner during pregnancy, distance to the clinic, and community acceptability. There is the need for all these stakeholders to make conscious efforts to achieve high male involvement in antenatal care.

The healthcare delivery system is best placed to spearhead male partner involvement in ANC. Health staff attitudes need to be changed to friendlier one to foster greater male involvement. Provision of service should also be carried in an expedited manner to reduce the waiting time of clients. Negative socio-cultural norms can also be addressed as men, their partners, and healthcare providers meet often to interact. These issues, as highlighted by this research, will help in formulating policies that will remove the barriers to male partner involvement in ANC and lead to the overall improvement in maternal and child health.

\section{Competing Interest}

The authors declare that they have no competing interest.

\section{Acknowledgment}

We thank Ernestina Atanga and Lamisi Akugri for their support. We are also grateful to all the participants for their patience and participation.

\section{References:}

1. Aborigo, R., Reidpath, D., Oduro, A., \& Allotey, P. (2018). Male involvement in maternal health: Perspectives of opinion leaders. $B M C$ Pregnancy and Childbirth, 18, 3.

2. Adongo, P., Tapsoba, P., Phillips, J., Tabong, P., Stone, A., Kuffour, 
E., Esantsi, S., \& Akweongo, P. (2013). The role of community-based health planning and services strategy in involving males in the provision of family planning services: A qualitative study in Southern Ghana. Reproductive Health, 10, 36.

3. Allendorf, K. (2007). Couples' Reports of Women's Autonomy and Health-care Use. Studies in Family Planning, 38(1), 35-46.

4. Atuahene, M., Arde-Acquah, S., Atuahene, N., Adjuik, M., \& Ganle, J. (2017). Inclusion of men in maternal and safe motherhood services in inner-city communities in Ghana: Evidence from a descriptive cross-sectional survey. BMC Pregnancy and Childbirth, 17, 419.

5. Babalola, S. \& Fatusi, A. (2009). Determinants of use of maternal health services in Nigeria- looking beyond individual and household factors. BMC Pregnancy Childbirth, 9, 43.

6. Bougangue, B. \& Ling, H. (2017). Male involvement in maternal healthcare through Community- based Health Planning and Services: The views of the men in rural Ghana. BMC Public Health, 17, 693.

7. Byamugisha, R., AAstrøm, A., Ndeezi, G., Karamagi, C., Tylleskär, T., \& Tumwine, J. (2011). Male partner antenatal attendance and HIV testing in eastern Uganda: a randomized facility-based intervention trial. Journal of the International AIDS Society, 14(1), 43.

8. Byamugisha, R., Tumwine, J., Semiyaga, N., \& Tylleskär, T. (2010). Determinants of male involvement in the prevention of mother-tochild transmission of HIV programme in Eastern Uganda: A crosssectional survey. Reproductive Health, 7, 12.

9. Dharma, N. (2013). Involvement of males in antenatal care, birth preparedness, exclusive breast feeding and immunizations for children in Kathmandu and Nepal. BMC Pregnancy and Child Birth, 13, 14.

10. Du Prel, J., Röhrig, B., Hommel, G., \& Blettner, M. (2010). Choosing Statistical Tests. Deutsches Aerzteblatt Online, 107(9), 343-348.

11. Fekede, A., Ayele, G., \& Yadeta, D. (2014). Male partners involvement in maternal ANC Care: The View of women attending ANC in hararipublic health institutions, Eastern Ethiopia. Science Journal of Public Health, 2(3), 182188.

12. Ganle, J. \& Dery, I. (2015). What men don't know can hurt women's health: a qualitative study of the barriers to and opportunities for men's involvement in maternal healthcare in Ghana. Reprod Health, 12, 93.

13. Ganle, J., Dery, I., Manu, A., \& Obeng (2016). If I go with him, I can't talk with other women': Understanding women's resistance to, and acceptance of, men's involvement in maternal and child healthcare in northern Ghana. Soc Sci Med, 166, 195-204.

14. Ghana Health Service (2018). THE health sector in Ghana facts and figures. 
http://ghanahealthservice.org/downloads/Facts+Figures_2018.pdf

15. Jambeidu, S. (2017). Determinants of male involvement in antenatal care in the Bawku municipality, Upper East region Ghana. University of Ghana.

16. Jennings, L., Na, M., Cherewick, M., Hindin, M., Mullany, B., \& Ahmed, S. (2014). Women's empowerment and male involvement in antenatal care : analyses of Demographic and Health Surveys ( DHS ) in selected African countries. BMC Pregnancy and Child Birth, 14, 297.

17. Kululanga, L., Sundby, J., Malata, A., \& Chirwa, E. (2012). Male Involvement in Maternity Health Care in Malawi. African Journal of Reproductive Health, 16(1), 145-158.

18. Kwambai, T., Dellicour, S., Desai, M., Ameh, C., Person, B., Achieng, F., Mason, L., Laserson, K., \& Kuile, F. (2013). Perspectives of men on antenatal and delivery care service utilisation in rural western Kenya: A qualitative study. BMC Pregnancy and Childbirth, 13, 134. Retrieved from BMC Pregnancy and Childbirth

19. Lewis, S., Lee, A., \& Simkhada, P. (2015). The role of husbands in maternal health and safe childbirth in rural Nepal: A qualitative study. BMC Pregnancy and Childbirth, 15(162).

20. Mersha, A. (2018). Male involvement in the maternal health care system: implication towards decreasing the high burden of maternal mortality. BMC Pregnancy and Childbirth, 18, 493.

21. Miltenburg, A., Van Der Eem, L., Nyanza, E., Van Pelt, S., Ndaki, P., Basinda, N., \& Sundby, J. (2017). Antenatal care and opportunities for quality improvement of service provision in resource limited settings: A mixed methods study. PLoS ONE, 12(12).

22. Muki, M. (2009). Factors affecting utilization of natal services by HIV pregnant women in Jnja District, Uganda. Retrieved from http://makir.mak.ac.ug/handle/10570/995?show=full

23. Mullany, B., Hindin, M., \& Becker, S. (2005). Can women 'e autonomy impede male involvement in pregnancy health in Katmandu, Nepal? Social Science \& Medicine, 61(9), 1993-2006.

24. Mullick, S., Kunene, B., \& Wanjiru, M. (2005). Involving men in maternity care: Health service delivery issues. Agenda, Special Focus: Gender, Culture and Rights, 124-135.

25. Sinha, D. (2008). Empowering Communities to Make Pregnancy Safer: An intervention in rural Andhra Pradesh. New Delhi.

26. Steen, M., Downe, S., Bamford, N., \& Edozien, L. (2012). Not-patient and not-visitor: A metasynthesis fathers ${ }^{\text {ee }}$ encounters with pregnancy, birth and maternity care. Midwifery, 28, 422-431.

27. Story, W. \& Burgard, S. (2012). Couples reports of household 
decision-making and the utilization of maternal health services in Bangladesh. Social Science \& Medicine, 75(12), 2403-2411.

28. Sumankuuro, J., Crockett, J., \& Wang, S. (2017). The use of antenatal care in two rural districts of Upper West Region, Ghana. PloS One, 12(9).

29. Tweheyo, R., Konde-Lule, J., Tumwesigye, N., \& Sekandi, J. (2010). Male partner attendance of skilled antenatal care in peri-urban Gulu district. Northern Uganda. BMC Pregnancy Childbirth, 10, 53.

30. WHO (2016a). Recommendation on antenatal care contact schedules. Retrieved from https://extranet.who.int/rhl/topics/improving-healthsystem-performance/who-recommendation-antenatal-care-contactschedules

31. WHO (2016b). WHO recommendations on antenatal care for a positive pregnancy experience. Retrieved from https://apps.who.int/iris/bitstream/handle/10665/250796/9789241549 912eng.pdf;jsessionid=636BBECFCC3A9CDEE7E9B2AEF69A3F8 $\mathrm{C}$ ?sequence $=1$ 